\title{
Counting only the hits? The risk of underestimating the costs of stringent climate policy
}

\section{A letter}

\author{
Massimo Tavoni · Richard S. J. Tol
}

Received: 12 October 2009 / Accepted: 17 April 2010 / Published online: 8 May 2010

(C) The Author(s) 2010. This article is published with open access at Springerlink.com

\begin{abstract}
This paper warns against the risk of underestimating the costs-and the uncertainty about the costs - of achieving stringent stabilization targets. We argue that a straightforward review of integrated assessment models results produces biased estimates for the more ambitious climate objectives such as those compatible with the $2^{\circ} \mathrm{C}$ of the European Union and the G8. The magnitude and range of estimates are significantly reduced because only the most optimistic results are reported for such targets. We suggest a procedure that addresses this partiality. The results show highly variable costs for the most ambitious scenarios.
\end{abstract}

\section{Introduction}

As the predictions about climate change are becoming direr and support for climate policy is growing across the political spectrum, the long-term goals for greenhouse gas emission reduction are getting more ambitious. The targets that are now on the political agenda were deemed unlikely only 5 years ago. As a result, there is only a thin (though growing) body of literature that has assessed the costs of meeting

M. Tavoni (西)

Princeton Environmental Institute, Princeton University, Princeton, NJ, USA

e-mail:mtavoni@princeton.edu

M. Tavoni

Fondazione Eni Enrico Mattei (FEEM), Milan, Italy

R. S. J. Tol

Economic and Social Research Institute, Dublin, Ireland

R. S. J. Tol

Institute for Environmental Studies, Vrije Universiteit, Amsterdam, The Netherlands

R. S. J. Tol

Department of Spatial Economics, Vrije Universiteit, Amsterdam, The Netherlands 
these aspirations. This poses important risks, since the most policy-relevant part of the literature is characterized by fewer studies. This note analyses the estimates of climate policy costs and highlights the risks of dealing with incomplete samples. We argue that when a straightforward review of the model results is undertaken, a reporting bias is likely to occur, with an inadvertent partiality in policy advice.

The bias in policy advice comes about as follows. Analysts run their model using a central scenario that is considered to be most relevant to policy. Sensitivity analyses are done with more stringent and more lenient targets, but results are reported in less detail. A careful modeler would realize that more stringent targets would take the model further away from its domain of calibration, and would hesitate to publish such results so as to maintain academic credibility. Most importantly, for those models that are more conservative in terms of the ability and costs of reducing emissions, stringent scenarios are often not attainable or infeasible, and thus simply do not appear in the literature. Until recently, the standard choice for a central scenario aimed at stabilizing atmospheric carbon dioxide at a concentration of 550 ppm (Weyant 2004; Weyant et al. 2006; Weyant and Hill 1999). The policy debate has now moved to a stabilization of greenhouse gas concentrations at $450 \mathrm{ppm} \mathrm{CO}_{2}$ equivalent as a central case (MEF 2009; CEC 2005). In order to be able to satisfy this new policy demand, the models that have analyzed the more ambitious policies have been pushed towards implementing more optimistic assumptions about the range and availability of their mitigation portfolio, which has the effect of lowering the costs of climate policies. In summary, published results for stringent emission targets are fewer and tend to be disproportionally based on models that have low policy costs.

This is best illustrated with the Summary for Policy Makers of working group III of the Fourth Assessment Report of the Intergovernmental Panel on Climate Change (Barker et al. 2007; IPCC 2007, Tables SPM.4,SPM.5 and SPM.6). Emission reduction costs are reported for three alternative targets. While 118 results were available for targets in the range of $3.2^{\circ} \mathrm{C}$ to $4.0^{\circ} \mathrm{C}$ warming, there were only six estimates of the costs of keeping warming in the range of $2.0^{\circ} \mathrm{C}$ to $2.4^{\circ} \mathrm{C}$. According to the reported results, moving from a $3.6^{\circ} \mathrm{C}$ to a $3.0^{\circ} \mathrm{C}$ target would double the abatement costs. Moving from a $3.0^{\circ} \mathrm{C}$ to a $2.2^{\circ} \mathrm{C}$ target would increase costs by $37.5 \%$ only. This less than proportional increase is at odds with the specification of the underlying models, for which strict convexity in abatement costs means that stringent targets have higher and accelerating costs. In the same report, the convexity in abatement cost curves is shown to hold for most the reporting models, summarized by the statement that "the majority of studies find that GDP losses increase with the stringency of the target". ${ }^{1}$ Indeed, looking at the cost curves ${ }^{2}$ it appears that the few model runs that simulated the most stringent climate policies were not representative of the larger sample. That is, that selection bias occurred because only scenarios with lower than average emission reduction costs reported results for the most stringent targets. Such selection bias is potentially misleading for policy makers (Tol 2007).

This paper is meant to shed light on this issue by quantifying the bias that would occur in a meta-analysis of cost estimates of a range of climate policies carried out by

\footnotetext{
${ }^{1}$ Chapter 3, "Issues related to mitigation in the long-term", p. 204.

${ }^{2}$ See Fig. 3.25 (IPCC 2007).
} 
a number of integrated assessment models. We show that the bias can be significant and propose a simple correcting procedure. This paper proceeds as follows. We first discuss the data used in this paper, and then present a method to correct for selection bias. We apply this method and analyze the results before drawing conclusions.

\section{Data and selection bias}

We avail of a recent data set of model results. The data result from the 22nd round of model comparison led by the Energy Modeling Forum (EMF22). We focus on the international scenarios as this is the richest set of data. ${ }^{3}$ Details of the scenarios and of the main implications can be found in Clarke et al. (2009). Ten models ${ }^{4}$ from across the rich world ran ten scenarios, that had three alternative levels of atmospheric stabilization in 2100 (450, 550 and $650 \mathrm{CO} 2$-eq ppm), allowed or disallowed overshooting the target in the intermediate run, and had two alternative specifications of international participation (global emission reduction from 2012 onwards versus delayed participation by developing countries). The modelers were explicitly asked to run all scenarios, including the more stringent ones; although they did not report results in case of infeasibility ${ }^{5}$ or unrealistically high initial carbon price (above $1000 \$ / \mathrm{tCO}_{2}$ in 2012), they did report the fact that the target was "infeasible" according to their model.

We focus our attention on the economic implications of climate stabilization scenarios. Nine out of ten ${ }^{6}$ models reported economic costs expressed either-or both-as GDP loss and abatement costs, two common metrics for macro-economic and energy system models. To maximize consistency in the use of the cost metrics, we have used change in GDP for all the (seven) models that reported it and total abatement cost in the remaining (two) cases. Policy costs have been calculated relative to the baseline, actualized in net present values using a $5 \%$ discount rate.

Since some models reported more than one case for each scenario, we have 11 runs for each of the 10 scenarios, for a total of 110 potential observations. However, only 68 are reported in reality, since some scenarios could not be run by some models. The first row of Table 1 shows the distribution of model runs that were completed, by scenario; it indicates that the more ambitious the scenarios, the fewer the observations, since more and more models found them unattainable. The density of feasible runs is particularly low for the 450-escenarios, which is troubling because these are the only ones consistent with the $2^{\circ} \mathrm{C}$ threshold.

\footnotetext{
${ }^{3}$ Data is publicly available at the following website http://emf.stanford.edu/events/emfbriefing_on_ climate_policy_scenarios_us_domestic_and_international_policy_architectures/.

${ }^{4}$ ETSAP-TIAM (Loulou et al. 2009), FUND (Tol 2009), GTEM (Gurney et al. 2009), IMAGE (van Vliet et al. 2009), MERGE (Blanford et al. 2009), MESSAGE (Krey and Riahi 2009), MINICAM (Calvin et al. 2009a), POLES (Russ and van Ierland 2009), SGM (Calvin et al. 2009b) and WITCH (Bosetti et al. 2009).

${ }^{5}$ Either because of "physical infeasibility" (the forcing target was exceeded prior to the initiation of mitigation) or "model solution" (failure in the solution mechanism).

${ }^{6}$ With the exception of POLES.
} 


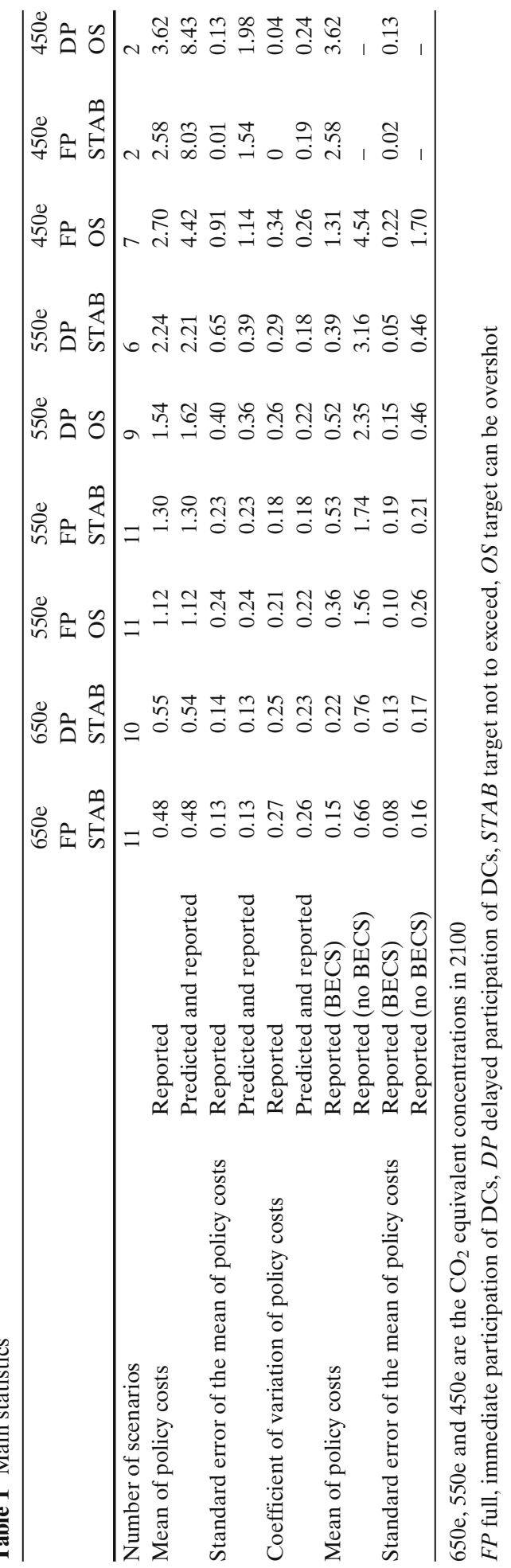




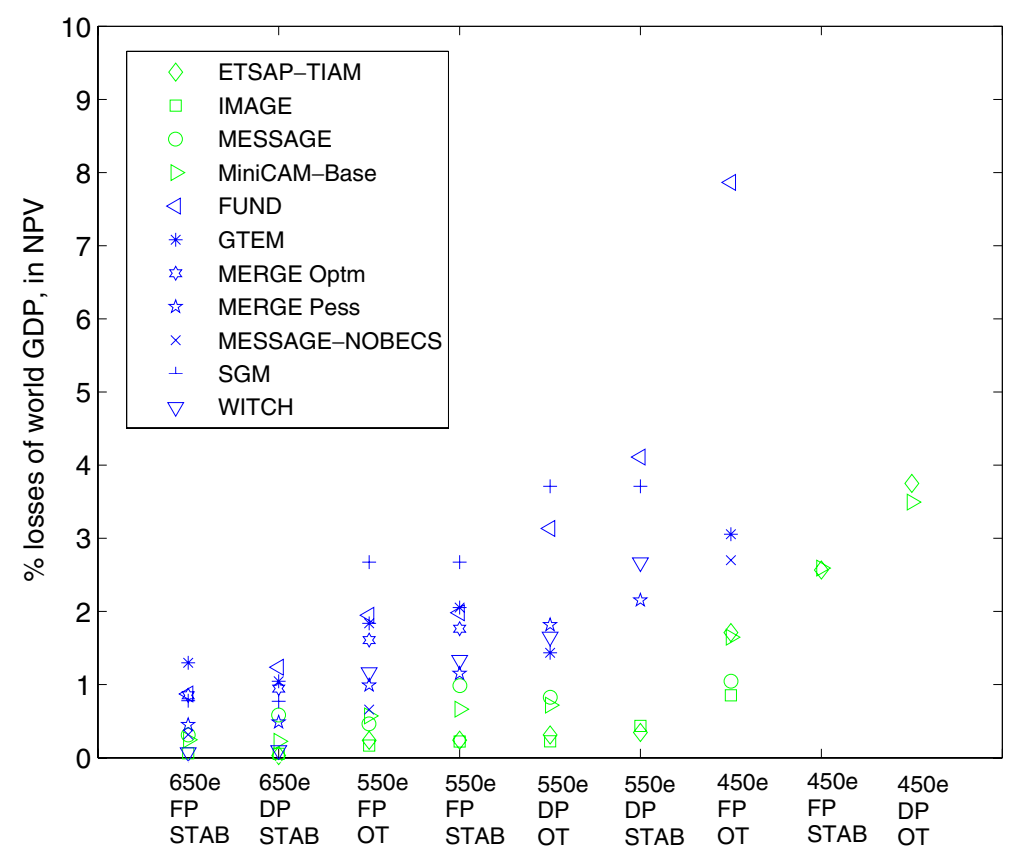

Fig. 1 Policy costs for the EMF22 data set by model run. Green colors indicate models with BECS and blue models without BECS. Scenario legend as in Table 1

This is also clear from Fig. 1, which shows the policy costs for all scenario runs. Abatement costs are convex in the policy objective, but two distinct patterns are revealed, depending on whether the models feature or not bio-energy with carbon capture and storage (BECS; Rhodes and Keith 2005). Incidentally, in this dataset, this distinction almost coincides with the one of bottom-up versus top down models, which is also known to be a source of difference in the policy costs, with top-down economic models reporting higher figures. The important feature to notice here is that stringent scenarios are simulated by the models that display costs that are lower than the average of the whole sample. Thus, a meta-analysis of such model results that took the mean of the sample would inevitably be plagued by selection bias. This could lead to a distortion in the statistical analysis, with important repercussions for policy advice.

\section{Accounting for the bias}

Correcting for the bias is not straightforward. Replacement methods such as imputation cannot be used, precisely because there is a systematic relation between the causes of data being missing and the missing data, that is the values are not missing at random. In such cases, a model for filling in the missing observations needs to be devised. Essentially, we conduct a meta-analysis (Barker et al. 2002; Fischer and Morgenstern 2006; Kuik et al. 2009; Repetto and Austin 1997) and use the estimated 
Table 2 Regression results for the natural logarithm of the net present value of abatement costs as a percentage of the net present value of the gross domestic product in the no-policy scenario

\begin{tabular}{lclr}
\hline Variable & Coefficient & Standard error & t-statistic \\
\hline Radiative forcing & -1.65 & 0.127 & -13.0 \\
Delayed participation & 0.423 & 0.124 & 3.41 \\
Overshoot & -0.910 & 0.270 & -3.37 \\
BECS & -1.66 & 0.297 & -5.59 \\
ETSAP & 0.290 & 0.242 & 1.20 \\
FUND & 0.721 & 0.305 & 2.36 \\
GTEM & 0.606 & 0.301 & 2.02 \\
IMAGE & $($ dropped) & & \\
MERGE (opt) & 0.676 & 0.334 & 2.03 \\
MERGE (pess) & 0.137 & 0.312 & 0.44 \\
MESSAGE & 1.581 & 0.274 & 5.77 \\
MESSAGE (NoBS) & $($ dropped) & & \\
MiniCAM & 1.204 & 0.242 & 4.98 \\
SGM & 0.792 & 0.315 & 2.52 \\
WITCH & -0.363 & 0.313 & -1.16 \\
Adj. R $^{2}$ & 0.842 & Root MSE & 0.459 \\
\hline
\end{tabular}

model to impute the missing observations. We propose a simple OLS regression ${ }^{7}$ between the (natural logarithm of) the policy costs and a series of independent variables that include the stringency of the climate target in radiative forcing, model dummies, a delayed participation dummy, an overshoot dummy, and a dummy for BECS (which is not statistically distinguishable from the one on bottom-up modeling structure).

The regression results shown in Table 2 confirm the intuition, highlighted in the overview paper to the EMF22 exercise (Clarke et al. 2009), that the climate objective, the possibility to temporarily overshoot the target, and the rate of participation of developing countries are main driving forces of policy costs. In addition, BECS—or equivalently the bottom-up structure-have a significant effect on policy costs, since they allow for more flexible carbon mitigation pathway.

This simple estimation allows us to predict policy costs for those models that were unable to run the more stringent scenarios, thus addressing the selection bias issue. Results are presented in Fig. 2, where we compare the original dataset with the one augmented with predictions generated by our simple model. The figure indicates that correcting for selection bias leads to a significant upward revision of the estimates of macro-economic implications of stringent climate policies. Policy costs for the 450 $\mathrm{CO}_{2}$ e cases rise several fold, especially for the two more ambitious scenarios, that were originally dealt with by only two models.

Most importantly, accounting for the bias greatly increases the uncertainty around the costs. Relying on a subset of models is dangerous in that it can reduce the range of cost estimates, especially if the models share similar assumptions, which we have shown to be true for this experiment. Supplementing the data with our predicted

\footnotetext{
${ }^{7} \mathrm{We}$ also experimented with the Heckman sample selection technique, a model for heteroskedasticity, and kernel density estimators but did not find significant results. There are too few data given the number of model/scenario combinations, so that we can only estimate a basic model.
} 


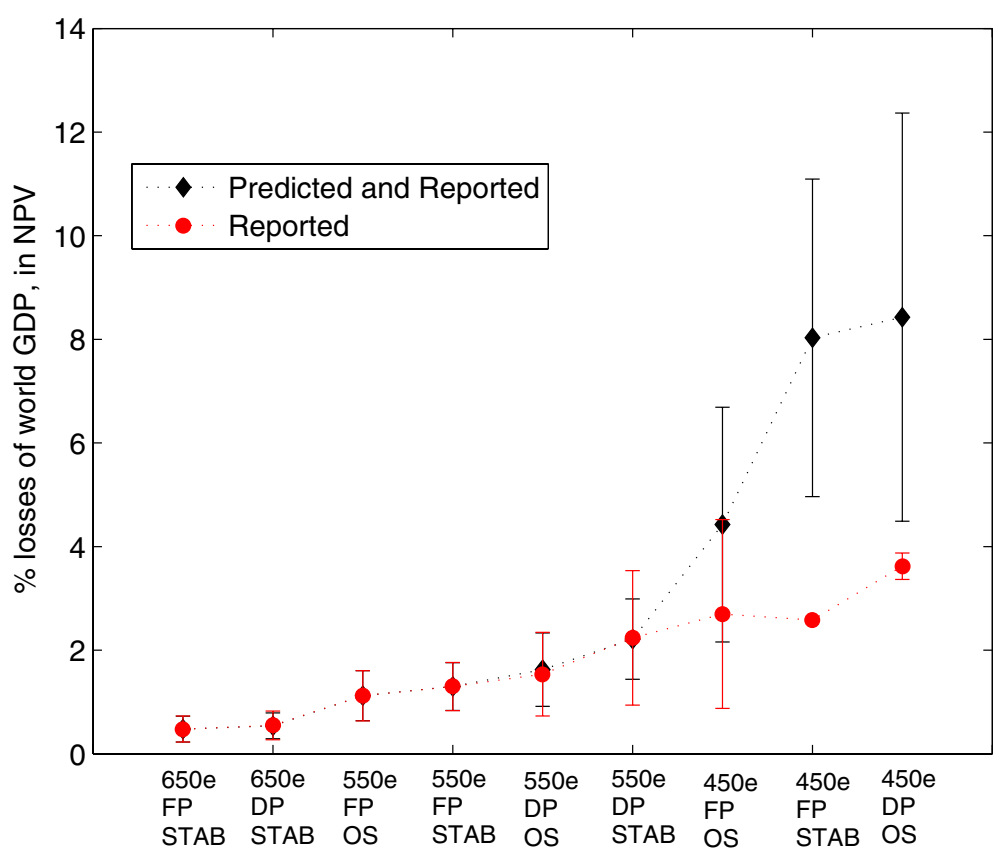

Fig. 2 Policy costs: mean and two standard errors of the mean (95\%), for the original EMF22 data set (reported) and the one where missing values have been predicted (predicted and reported)

values generates a much wider range of estimates. Figure 2 and Table 1 show that the variability across models tends to diminish in the observed datasets for the most ambitious scenarios, given that the low number of models that are able to solve them reported similar values. This feature is corrected when we predict the behavior of the more conservative models into the more ambitious schemes.

\section{What drives the costs difference?}

Since we have shown that different subsets of models generate significantly different answers regarding the economic impact of climate policies, it is interesting to understand the main drivers of the discrepancy. The distinction between bottomup and top-down models has been emphasized in previous model comparisons. The presence of zero-carbon backstop technology has also been known to be a key driver of results (Repetto and Austin 1997). The joint role of both effects is clear from Fig. 1, with models that feature BECS or have a bottom-up specification reporting lower policy costs.

In order to better grasp the relevance of these underlying forces, we carry out an experiment in which we predict what would happen if all models, in all scenarios, were forced to have either a BECS/bottom-up or a NO BECS/top-down structure. These two polar cases are shown in Fig. 3. As expected, the costs and their ranges are significantly affected by which specification is assumed. Differences are particularly noteworthy for the low stabilization targets, though they are visible across all 


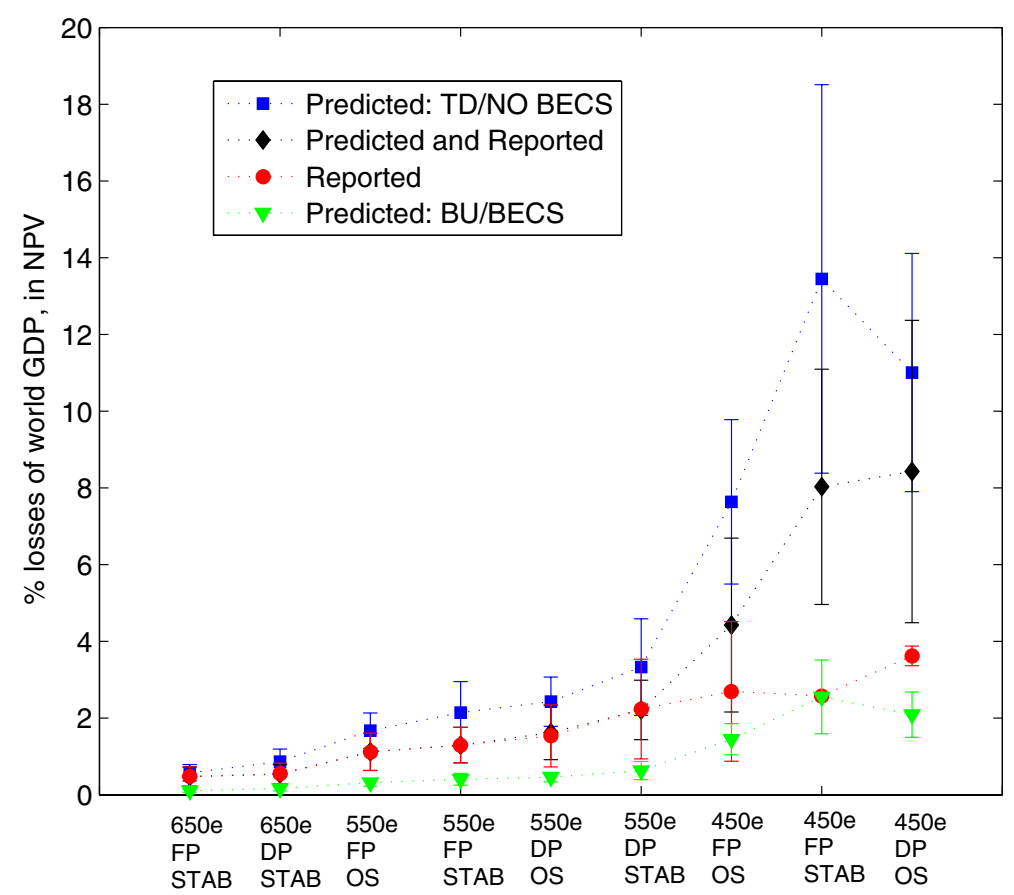

Fig. 3 Policy costs as in Fig. 2, supplemented with two limiting cases

scenarios. Given the strong significance of the overshoot dummy variable, a decrease in costs is predicted for the rightest scenario. Two main points can be inferred from this exercise.

Carbon absorption technology BECS, at the level assumed by the models which feature it in the EMF22 exercise, is an important determinant of the costs and feasibility of achieving ambitious climate policies, since it allows to shift the mitigation burden over time. ${ }^{8}$ The scale of deployment of $\mathrm{CO}_{2}$ absorption is dramatic, with 15 (Calvin et al. 2009a, b) to 20 (Krey and Riahi 2009) GtCO2/year of net negative emissions globally. Besides the feasibility of safely storing such a large volume of $\mathrm{CO}_{2}$, this strategy would require a large, sustained supply of biomass, with potential consequences on land use and food supply (Hertel et al. 2009; Wise et al. 2009). On the other hand, no model features direct air capture of $\mathrm{CO}_{2}$ using chemical absorbers, a promising but unproven engineered sink (Keith et al. 2006; Keller et al. 2008; Lackner 2009; Stephens and Keith 2008).

In addition, the costs differences between the two limiting cases persist even for less ambitious climate scenarios such as 550-e and 650-e, for which BECS is less or not relevant. This emphasizes that the representation of the economy and the technology in the models remains a determinant source of difference across models irrespective of the assumptions about negative emission technologies. For

\footnotetext{
${ }^{8}$ Thus, using a discount rate for actualizing GWP losses lower than the standard 5\% would decrease the cost gap between the two cases.
} 
the ambitious climate policies, taking the reported values from the sample would correspond to assuming that all models featured the negative emission technologies and a bottom-up modeling structure.

\section{Summary and recommendations}

In this article, we have highlighted the risks of selection bias when comparing integrated assessment modeling results. Using a recent comparison exercise, we have illustrated that since stringent scenarios can be simulated only by the models that are more optimistic (in terms of technology substitutability, mitigation portfolio, baseline etc.), a meta-analysis of model results would inevitably be plagued by selection bias. We have shown that one method of correcting the bias would lead to decisively higher estimates for the costs and the range of costs of meeting stringent climate stabilization scenarios.

This article is meant to provide recommendations for the future analysis of integrated assessment models. We have shown that different representation of the economic activity and of decarbonization technologies have an important bearing on the costs of climate policies. Given the various ways models can differ from one another, comparison exercises are particularly important to identify robust findings across model specification, and are indeed at the heart of the reviewing work of the IPCC. The fourth assessment report suggested that caution was needed when interpreting the results of the more stringent climate policies, as a slim number of studied had been carried out at the time. However, approaches more formal than general warnings are needed when dealing with policy relevant issues such as the costs of climate protection. This is especially important when communicating uncertainties, which are easily lost in the executive summaries. This note has provided a first attempt to resolve the issue of selection bias in meta-analysis of integrated assessment estimates of climate mitigation costs.

Open Access This article is distributed under the terms of the Creative Commons Attribution Noncommercial License which permits any noncommercial use, distribution, and reproduction in any medium, provided the original author(s) and source are credited.

\section{References}

Barker T, Koehler J, Villena M (2002) The costs of greenhouse gas abatement: a meta-analysis of post-SRES mitigation scenarios. Environ Econ Policy Stud 5:135-166

Barker T, Bashmakov I, Alharthi A, Amann M, Cifuentes L, Drexhage J, Duan M, Edenhofer O, Flannery BP, Grubb MJ, Hoogwijk M, Ibitoye FI, Jepma CJ, Pizer WA, Yamaji K (2007) Mitigation from a cross-sectoral perspective. In: Metz B et al (eds) Climate change 2007: mitigationcontribution of working group III to the fourth assessment report of the intergovernmental panel on climate change. Cambridge University Press, Cambridge, pp 619-690

Blanford GJ, Richels RG, Rutherford TF (2009) Feasible climate targets: the roles of economic growth, coalition development and expectations. Energy Econ 31(Suppl 2):S82-S93

Bosetti V, Carraro C, Tavoni M (2009) Climate change mitigation strategies in fast-growing countries: the benefits of early action. Energy Econ 31(Suppl 2):S144-S151

Calvin K, Edmonds J, Bond-Lamberty B, Clarke L, Kim SH, Kyle P, Smith SJ, Thomson A, Wise M (2009a) 2.6: limiting climate change to 450 ppm CO2 equivalent in the 21st century. Energy Econ 31(Suppl 2):S107-S120 
Calvin K, Patel P, Fawcett A, Clarke L, Fisher-Vanden K, Edmonds J, Kim SH, Sands R, Wise M (2009b) The distribution and magnitude of emissions mitigation costs in climate stabilization under less than perfect international cooperation: SGM results. Energy Econ 31(Suppl 2):S187S197

CEC (2005) Winning the battle against global climate change. Communication from the Commission to the Council, the European Parliament, the European Economic and Social Committee and the Committee of the Regions COM(2005) 35 final, Commission of the European Communities, Brussels

Clarke L, Edmonds J, Krey V, Richels R, Rose S, Tavoni M (2009) International climate policy architectures: overview of the EMF 22 international scenarios. Energy Econ 31(S2):S64-S81

Fischer C, Morgenstern RD (2006) Carbon abatement costs: why the wide range of estimates? Energy J 272:73-86

Gurney A, Ahammad H, Ford M (2009) The economics of greenhouse gas mitigation: insights from illustrative global abatement scenarios modelling. Energy Econ 31(Suppl 2):S174-S186

Hertel TW, Rose S, Tol RSJ (eds) (2009) Economic analysis of land use in global climate change policy. Routledge, London

IPCC (2007) Summary for policymakers. In Metz B et al (eds) Climate change 2007: mitigationcontribution of working group III to the fourth assessment report of the intergovernmental panel on climate change. Cambridge University Press, Cambridge

Keith DW, Ha-Duong M, Stolaroff JK (2006) Climate strategy with CO2 capture from the air. Clim Change 74:17-45

Keller K, McInerney D, Bradford DF (2008) Carbon dioxide sequestration: how much and when? Clim Change 88:267-291

Krey V, Riahi K (2009) Implications of delayed participation and technology failure for the feasibility, costs, and likelihood of staying below temperature targets-Greenhouse gas mitigation scenarios for the 21st century. Energy Econ 31(Suppl 2):S94-S106

Kuik OJ, Brander L, Tol RSJ (2009) Marginal abatement costs of greenhouse gas emissions: a metaanalysis. Energy Policy 37(4):1395-1403

Lackner KS (2009) Capture of carbon dioxide from ambient air. Eur Phys J Special Topics 176:93106

Loulou R, Labriet M, Kanudia A (2009) Deterministic and stochastic analysis of alternative climate targets under differentiated cooperation regimes. Energy Econ 31(Suppl 2):S131-S143

MEF (2009) Declaration of the major economies forum on energy and climate. Major Economies Forum, L'Aquila

Repetto R, Austin D (1997) The costs of climate protection: a guide for the perplexed. World Resources Institute, Washington, DC

Rhodes JS, Keith DW (2005) Engineering economic analysis of biomass IGCC with carbon capture and storage. Biomass Bioenergy 29(6):440-450

Russ P, van Ierland T (2009) Insights on different participation schemes to meet climate goals. Energy Econ 31(Suppl 2):S163-S173

Stephens JC, Keith DW (2008) Assessing geochemical carbon management. Clim Change 90:217-242

Tol RSJ (2007) Biased policy advice from the intergovernmental panel on climate change. Energy Environ 18(7+8):929-936

Tol RSJ (2009) The feasibility of low concentration targets: an application of FUND. Energy Econ 31(S2):S121-S130

van Vliet J, den Elzen MGJ, van Vuuren DP (2009) Meeting radiative forcing targets under delayed participation. Energy Econ 31(Suppl 2):S152-S162

Weyant JP (2004) Introduction and overview. Energy Econ 26:501-515

Weyant JP, Hill JN (1999) Introduction and overview of the special issue. Energy journal special issue on the costs of the Kyoto protocol: a multi-model evaluation, pp vii-xliv

Weyant JP, de la Chesnaye FC, Blanford GJ (2006) Overview of EMF-21: multigas mitigation and climate policy. Energy J 3:1-32

Wise MA, Calvin KV, Thomson AM, Clarke LE, Bond-Lamberty B, Sands RD, Smith SJ, Janetos AC, Edmonds JA (2009) Implications of limiting CO2 concentrations for land use and energy. Science 324:1183-1186 